\title{
Native Aortic Valve Endocarditis-A Case Report
}

\author{
Ramachandran Muthiah \\ Zion Hospital, Azhagiamandapam, Kanyakumari District, India \\ Email: cardioramachandran@yahoo.co.uk
}

How to cite this paper: Muthiah, R. (2018) Native Aortic Valve Endocarditis-A Case Report. Case Reports in Clinical Medicine, 7, 483-504.

https://doi.org/10.4236/crcm.2018.79043

Received: July 8, 2018

Accepted: September 10, 2018

Published: September 13, 2018

Copyright $\odot 2018$ by author and Scientific Research Publishing Inc. This work is licensed under the Creative Commons Attribution International License (CC BY 4.0).

http://creativecommons.org/licenses/by/4.0/

\section{c) (i) Open Access}

\begin{abstract}
Introduction: To report a case of isolated "endocarditic" aortic regurgitation in a 17-year old female with infective vegetations on aortic valve. Case Report: A 17-year old female was admitted with features of heart failure and a febrile illness. Blood cultures were negative and ECG revealed normal. Echocardiography revealed a "kissing-type" of vegetation on the bicuspid aortic valve with severe aortic regurgitation and a dilated left ventricle with moderate dysfunction. Conclusion: The management of aortic insufficiency occurring in infective endocarditis may differ and the presence of intractable pulmonary edema or shock is a clear indication for prompt valve replacement. The traditional diagnostic criteria are insufficient to diagnose infective endocarditis and the modified Duke criteria provide high sensitivity and specificity over $80 \%$ for the diagnosis of native valve endocarditis with positive blood cultures.
\end{abstract}

\section{Keywords}

Bicuspid Aortic Valve, Infective Endocarditis, Kissing Vegetations, Acute Aortic Regurgitation, Aortic Valve Replacement

\section{Introduction}

Infective endocarditis is a microbial infection of a heart valve (native or prosthetic) or the mural endocardium, leading to tissue destruction and formation of vegetation. Its incidence varies from 1.7 - 7.2 cases/one lakh persons-year and the female to male ratio was 1:2 [1]. There are substantial changes in the epidemiology profile over the last few decades [2] as median age group has increased from 30 - 40 to 47 - 69 years and rheumatic heart disease is no longer the main risk factor in Western countries. The most common predisposing lesion for aortic valve endocarditis is congenitally bicuspid aortic valve (BCAV). Inadequate 
production of fibrillin-1 during valvulogenesis may disrupt the formation of aortic cusps, resulting in a bicuspid aortic valve and a weakened aortic root [3], which may complicate infective endocarditis in $9.5 \%$ of cases [4].

Isolated aortic regurgitation was found in only one-twenteeth of a large series of patients in India, 2.7\% of patients under 19 years in Brazil as a unique valvular dysfunction. The usual natural history is a long asymptomatic period in which mild-to-moderate regurgitation is well tolerated during the compensated phase and in adults, a rate of $<6 \%$ /year may progress to systolic dysfunction and patients with recurrent rheumatic episodes have a rapid progress and severe incompetence may become established within 1 to 2 years of the initial episode.

Infective endocarditis of aortic valve is also a major cause of isolated acute aortic regurgitation [5] and so this case had been reported.

\section{Case Report}

A 17-year old female was brought to the emergency room with a history of sudden onset of breathlessness. Her pulse rate was $87 \mathrm{bpm}$ and blood pressure $110 / 60 \mathrm{mmHg}$. She had a history of rheumatic fever during childhood, an episode of febrile illness for 10 days and taken antibiotic treatment recently. Blood chemistry revealed normal and blood cultures were negative. ECG revealed normal as shown in Figure 1 and X-ray chest revealed dilated LV (left ventricle) as in Figure 2. Physical examination revealed grade 3/6 early diastolic murmur over left mid sternal border, basal crackles over lung fields and no peripheral signs of wide pulse pressure. Transthoracic echocardiography revealed vegetations on anterior and posterior leaflets of aortic valve as in Figure 3 and Figure 4, with a "kissing-type" as in Figure 5, Figure 6 and Figure 7. The aortic valve was bicuspid with an attached vegetation as in Figure 8 in short axis view and in Figure 9 in apical view and it was severely regurgitant as in Figure 10 and Figure 11. The left ventricle is dilated as in Figure 12 with moderate LV dysfunction as in Figure 13. The thoracic aorta was prominent as in Figure 14 with a "holodiastolic flow reversal" as in Figure 15.

The patient was treated with digoxin $(0.25 \mathrm{mg}$, half daily), diuretics (Injection. Furosemide $20 \mathrm{mg}$ IV twice daily), ACE inhibitors (tablet. Enalapril $2.5 \mathrm{mg}$ twice daily) along with 2 weeks course of intravenous (IV) cefotaxime ( $1 \mathrm{~g}$ ) and amickacin $(500 \mathrm{mg})$ twice daily and advised aortic valve replacement at the earliest with lifelong penicillin prophylaxis and continuation of antibiotics for 6 weeks since the vegetations remain stable after 2 weeks of treatment, but without any embolic episodes.

\section{Discussion}

\subsection{Review of Literature}

In 1885, William Osler presented the first comprehensive description of endocarditis. Thereafter, the description of clinical features of infective endocarditis was largely based on data obtained several decades ago. At present, definite 


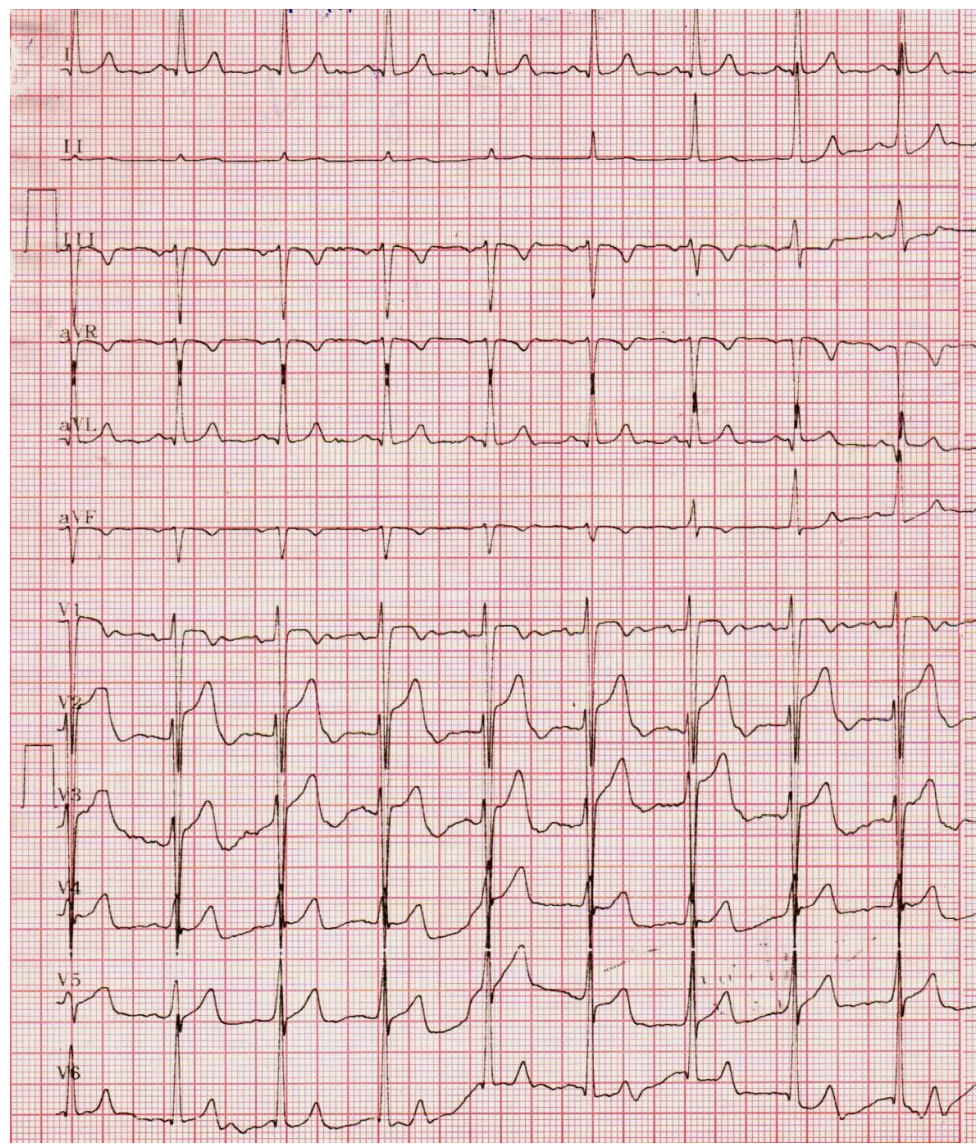

Figure 1. Showing the normal ECG in acute severe aortic regurgitation in a 17-year old female.

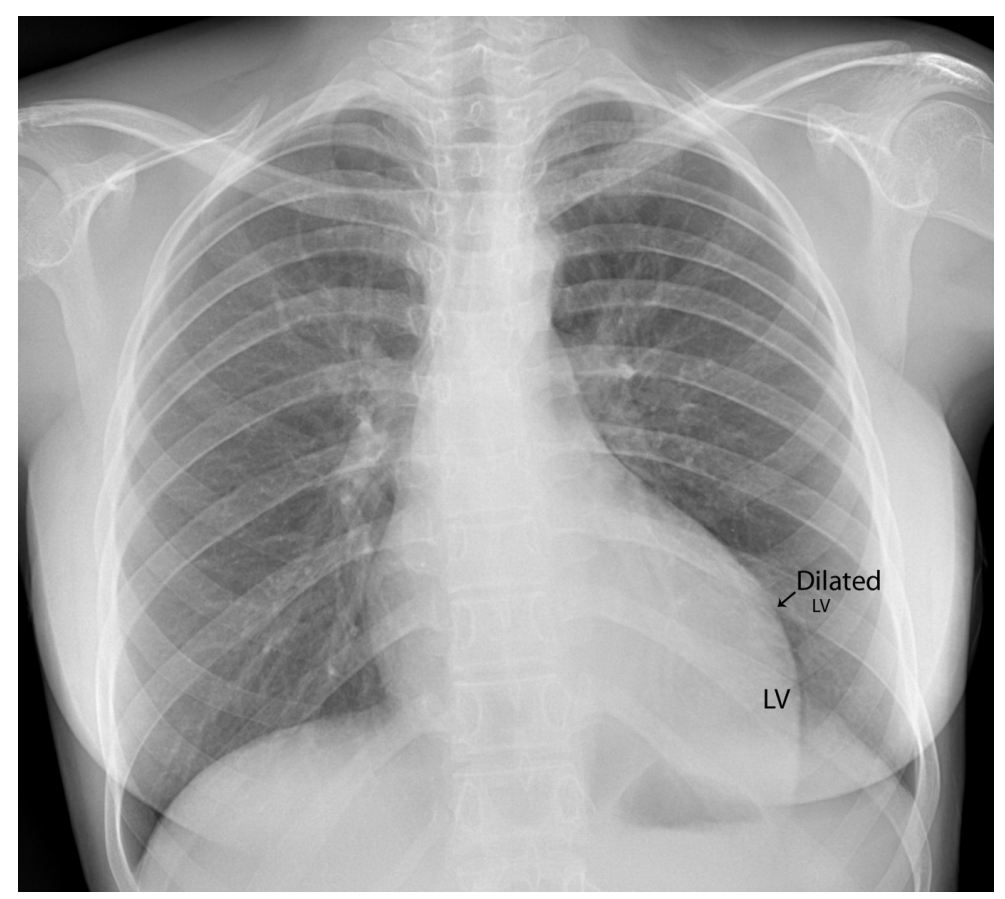

Figure 2. X-ray chest PA (postero-anterior) view showing the dilated left ventricle due to acute severe aortic regurgitation [6] in a 17-year old female. 


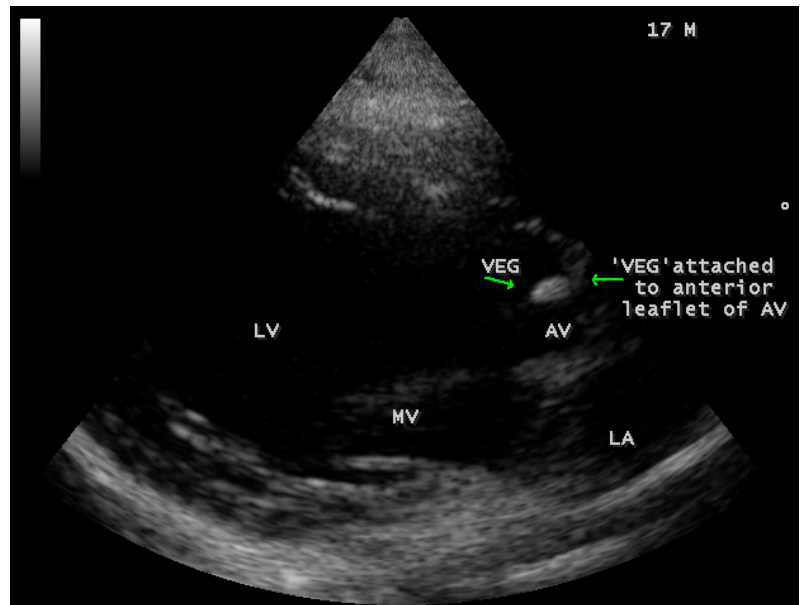

Figure 3. Parasternal long axis view showing the vegetation on the anterior leaflet of aortic valve (arrows) in a 17-year old female.

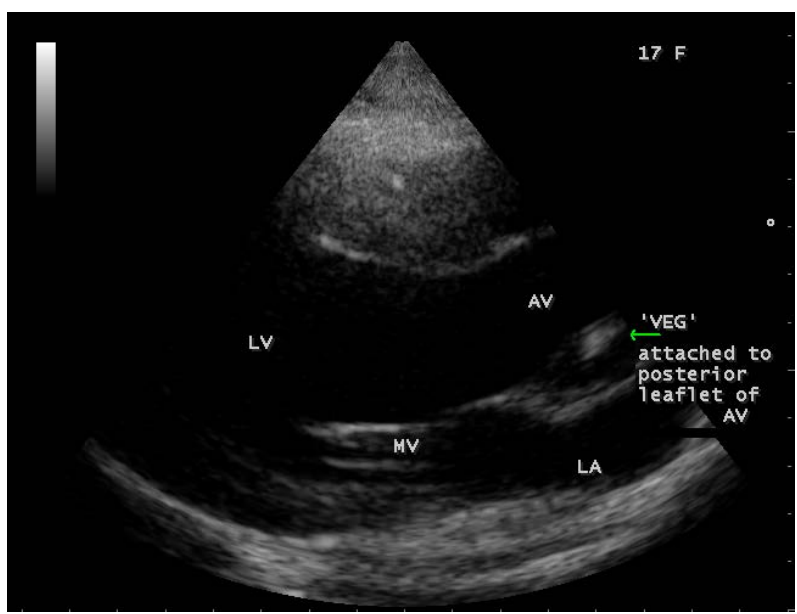

Figure 4. Parasternal long axis view showing the vegetation on the posterior leaflet of aortic valve (arrow) in a 17-year old female. AV-aortic valve.

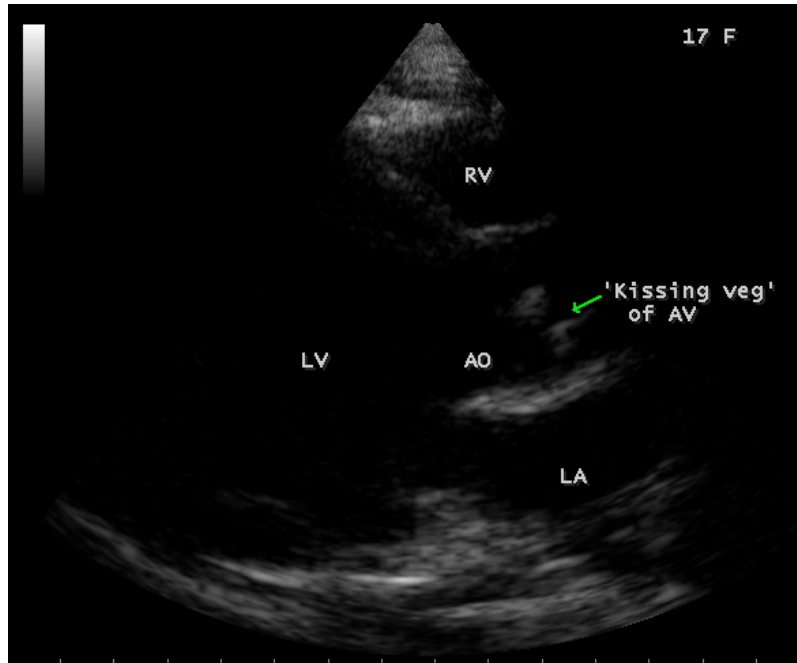

Figure 5. Parasternal long axis view showing the "kissing-type" of vegetations (arrow) on the aortic valve in a 17 -year old female. 


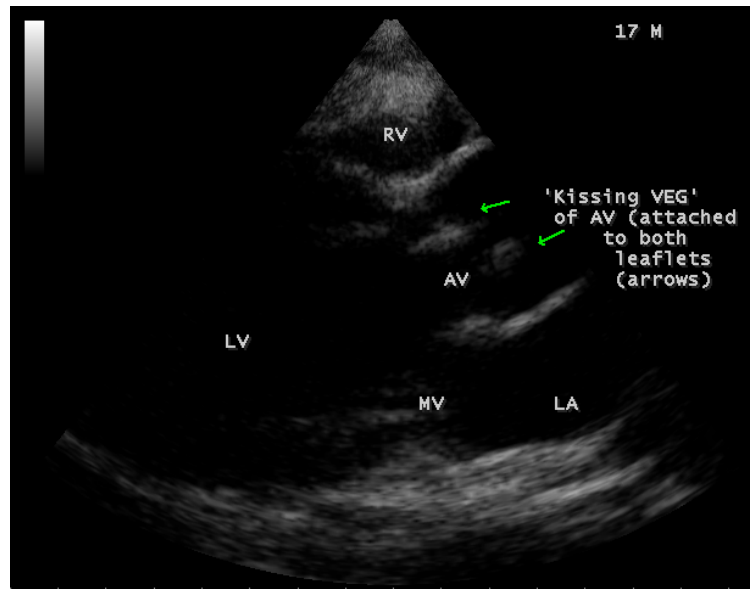

Figure 6. Parasternal long axis view showing the "kissing-type" of vegetations (arrows) on the aortic valve in a 17-year old female-large view.

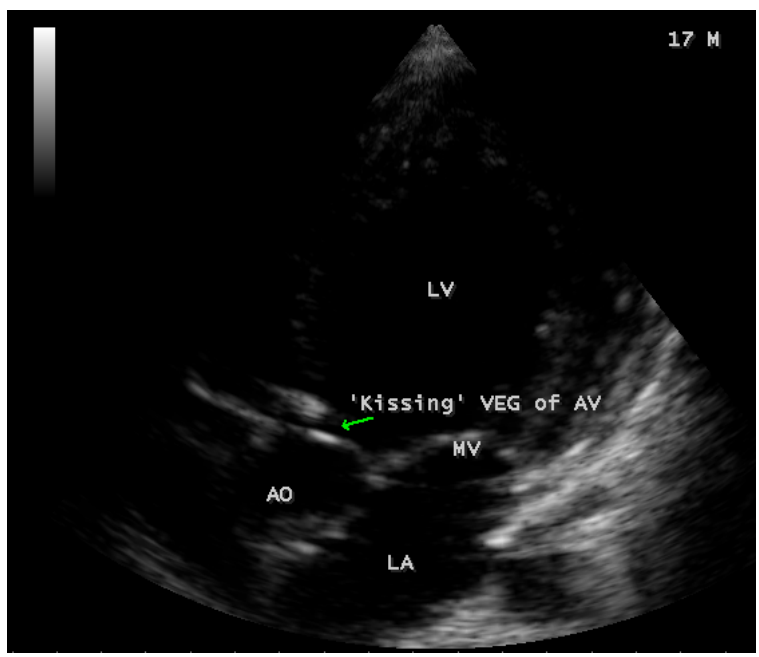

Figure 7. Apical view showing the "kissing-type" of vegetations (arrow) on the aortic valve in a 17 -year old female.

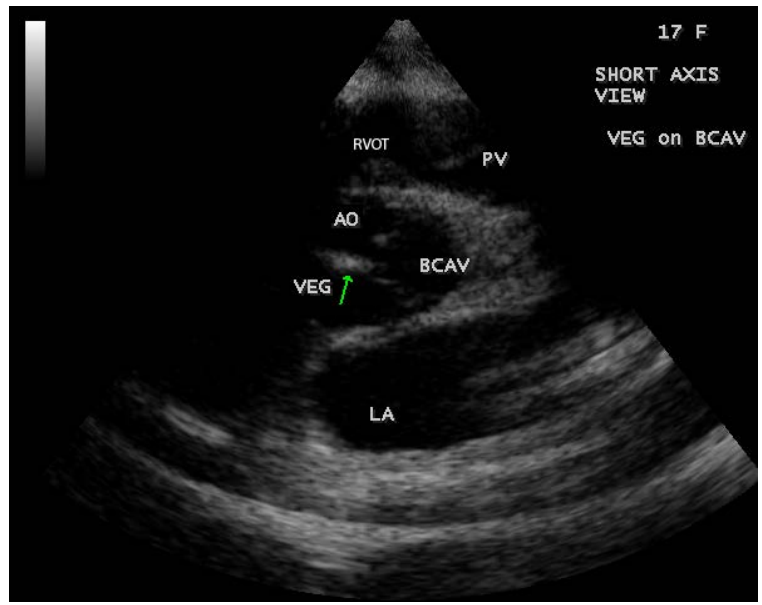

Figure 8. Short axis view showing the bicuspid aortic valve with vegetation (arrow) in a 17-year old female. AO_aorta, BCAV-bicuspid aortic valve, RVOT-right ventricular outflow tract, $\mathrm{PV}$ - pulmonary valve, LA-left atrium, VEG-vegetation. 


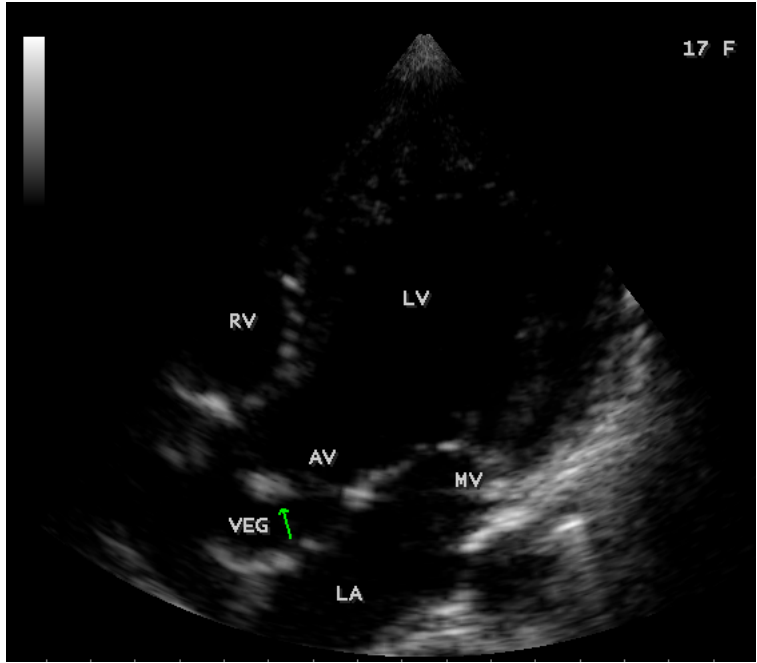

Figure 9. Apical view showing the vegetation on the aortic valve (arrow) in a 17-year old female.

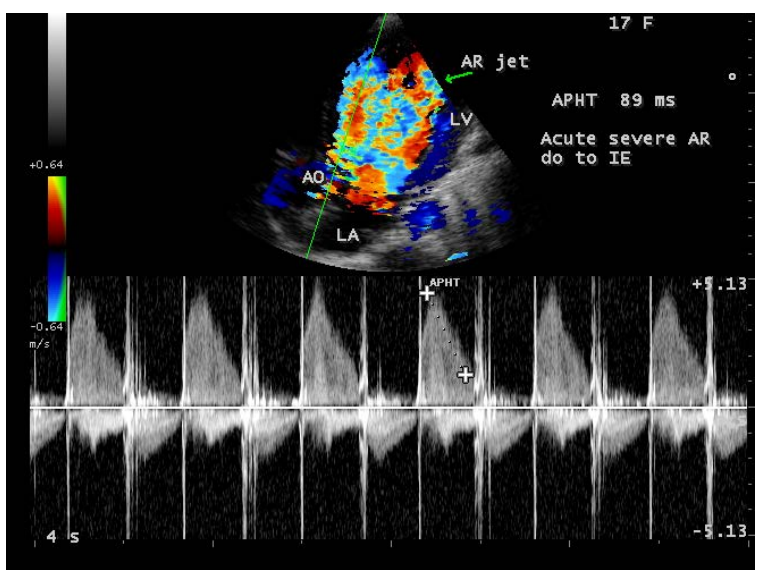

Figure 10. CW (continuous wave) Doppler showing the acute severe aortic regurgitation (arrow) jet (steep deceleration slope) in a 17-year old female. Shortened pressure half time (APHT-89 ms) is due to elevated LV diastolic pressure.

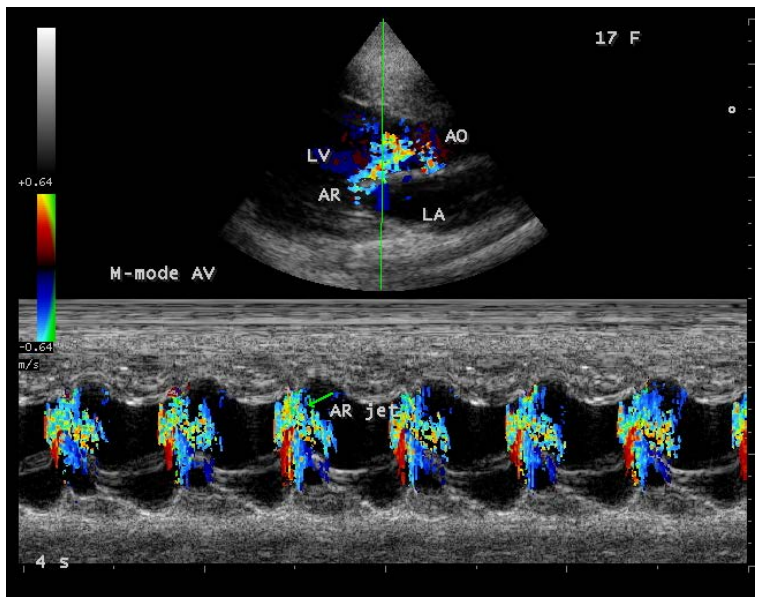

Figure 11. Color M-mode (green line) showing the acute severe aortic regurgitation (arrow-AR jet) in a 17-year old female. 


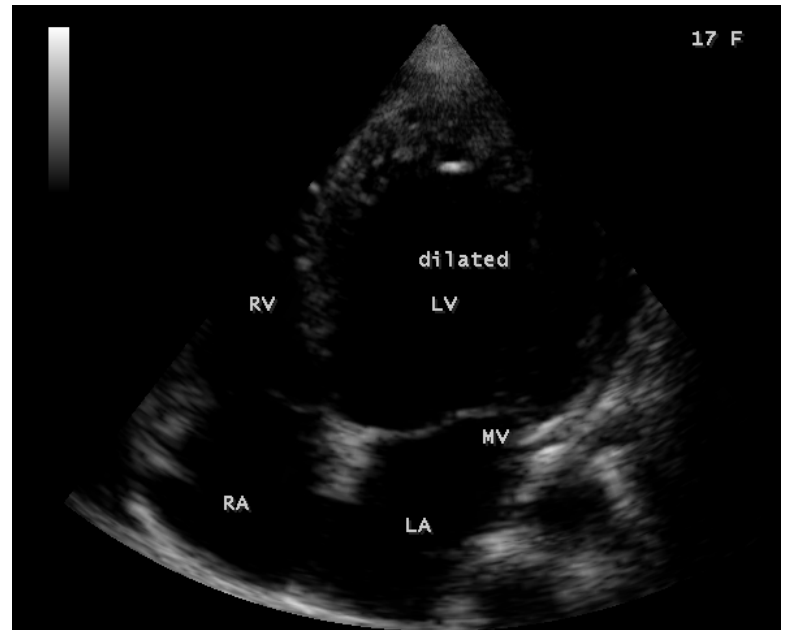

Figure 12. Apical view showing the dilated left ventricle and a normal left atrium in a 17 -year old female in acute severe aortic regurgitation.

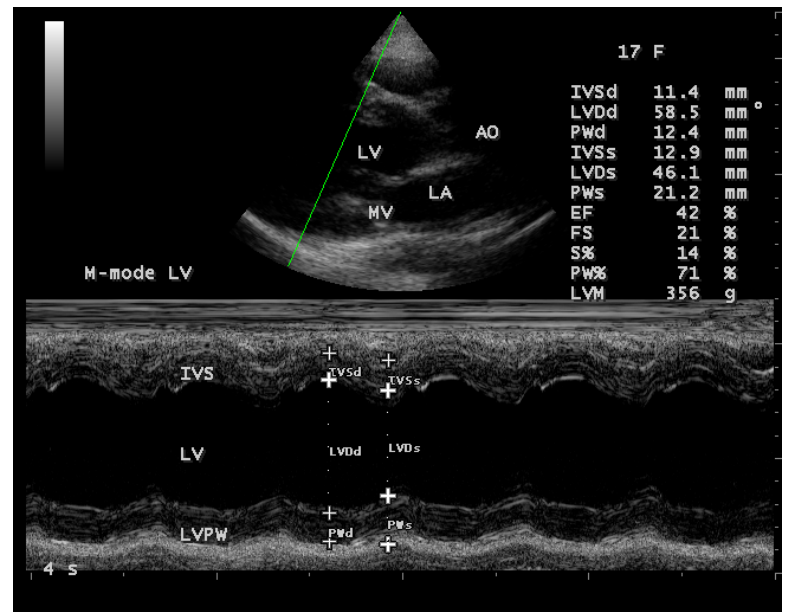

Figure 13. M-mode LV study (green line) showing moderate LV dysfunction with an ejection fraction of $42 \%$ in a 17 -year old female in acute severe aortic regurgitation.

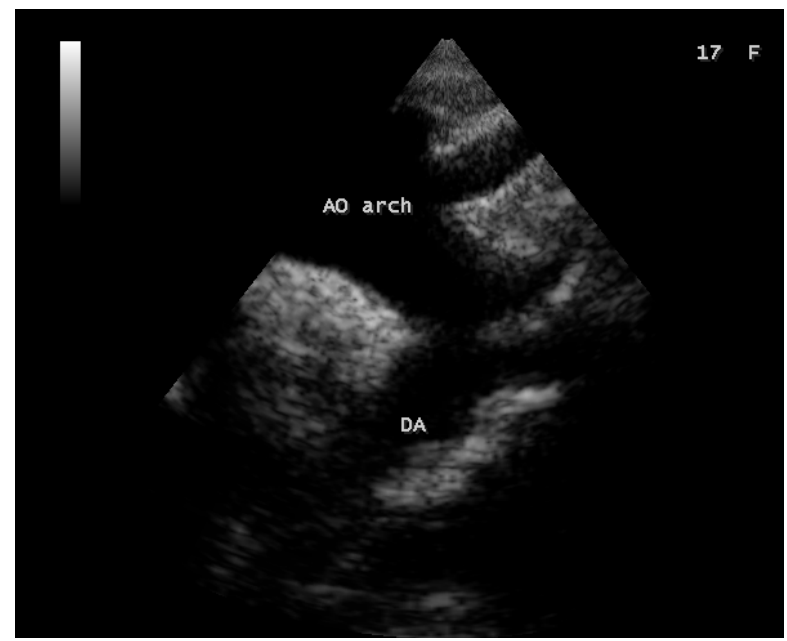

Figure 14. Suprasternal view showing the prominent aortic arch in a 17 -year old female in acute severe aortic regurgitation. 


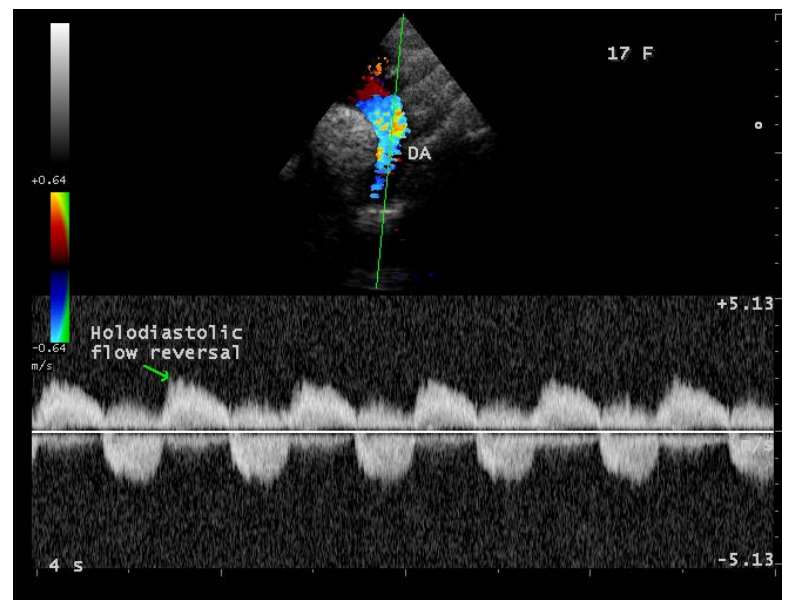

Figure 15. Suprasternal view showing the holodiastolic flow reversal (arrow) of severe aortic regurgitation [7] in a 17-year old female.

clinical evidence of vulnerable infection is based on retrieval of an organism via blood cultures. The ability of echocardiography to detect valvular vegetation was initially described by Dillon and coworkers [8] who identified characteristic thickened echoes, on the mitral and aortic leaflets in patients with tissue-documented valvular lesion.

\subsection{Etiopathogenesis}

The majority of cases of infective endocarditis are caused by gram-positive bacteria, the staphylococcus aureus is now more common than oral streptococci (streptococcus viridians) and it has become the most frequent microorganism causing infective endocarditis (31\% - 54\%). Methicillin-sensitive sytaphylococcus aureus (MSSA) is more frequently isolated in community-acquired infective endocarditis, affects mainly native valves, and it is associated with bacteremia of unknown origin, whereas Methicillin-resistant staphylococcus aureus (MRSA) is predominantly related to nosocomial infection, wound infection, IV catheters and surgical procedures. Viridans group is now less common (17\% - 26\%) and had partial resistance to antibiotics ("penicillin tolerence"). The slow-growing HACEK group is an unusual cause of infective endocarditis $(1.8 \%-3 \%)$ and affects mainly the native valves. Patients with IV drug abusers and long-term central venous catheters are at high risk of fungal infective endocarditis (1\% - 3\%), suspected in presence of bulky vegetation, metastatic infection, persistent invasion or embolization to large blood vessels. Whenever blood culture negative infective endocarditis occurs, other organisms such as coxiella burnetti, Brucella, Bartonella, Chlamydia, Streptococcus pneumoniae (often affects the aortic valve [9]) and Legionellae species must be considered.

When endothelium is damaged by high flow velocity jets, sterile thrombotic vegetation is formed, which facilitate bacterial adherence during transient bacteremia. Platelet and fibrin deposits at the damaged sites provide the nidus for the formation of vegetation, which causes tissue destruction, septic emboli and 
abscesses. Vegetation $>1 \mathrm{~cm}$ in diameter is associated with greatest risk of embolization [10] and 65\% of embolic events involve the central nervous system, mainly in the distribution of middle cerebral artery (90\%). Patients with staphylococcus aureus infective endocarditis have a significant higher incidence of neurologic sequelae (53\% - 71\%). Infected embolic material may reach the adventitial layer of an artery through the vasa vasorum, resulting destruction of adventitia and muscularis [11], leading to aneurysm formation [12], usually within 46 hours of embolization [13]. Cerebral infected aneurysms develop in $1 \%$ to $12 \%$ of cases of infective endocarditis and located on the peripheral branches of middle cerebral artery (55\%) [14], also in the secondary and tertiary branches in the region of Sylvian fissure [15] and it is multiple in $18 \%-28 \%$ of cases, had saccular type morphology [16] and 10\% of them will rupture. Infected intracranial aneurysms may leak slowly or enlarge before rupture and manifest as cranial nerve palsy, seizures, headache and nuchal rigidity due to meningeal irritation.

In addition, vegetations often occur in conjunction with ulceration, perforation, and even total destruction of valve leaflets [17], producing abrupt valvular regurgitation, manifested clinically by severe hemodynamic changes [18] [19]. Gross elevation of LVEDP (LV end-diastolic pressure), pulmonary hypertension and depressed cardiac output are the characteristic findings. Valvular destruction causing acute regurgitation is the most characteristic lesion leading to heart failure in native valve infective endocarditis [20] [21]. When there is rapid disruption of the anatomic integrity of the aortic valve, the sudden imposition of a large regurgitant volume causes precipitous increase in LV diastolic pressure and a decrease in forward stroke volume, leading to acute pulmonary edema and, on occasion, circulatory collapse. In acute aortic regurgitation, murmurs may not be easily audible, the pulse pressure is usually reduced due to reduction in stroke volume and increased peripheral vascular resistance. The characteristic physical findings of chronic, severe aortic regurgitation (AR) depend on a widened pulse pressure are often absent. Compensated tachycardia helps to shorten diastolic time available to regurgitation to occur and so the cardiac output is often maintained.

Early closure of mitral valve (ECMV) is a specific feature of acute onset, severe aortic regurgitation [22], first postulated by Austin Flint in 1886 [23] and observed echocardiographically by Pride in 1971 [24]. Normally, the mitral valve does not close until shortly after the onset of LV contraction, and leaflet closure occurs $40 \mathrm{~ms}$ after the onset of QRS complex in ECG. When the coaptation of both anterior and posterior mitral leaflets occur at or before the initial description of QRS ( 50 ms before the Q wave, but after the P wave, it is mild (grade I) and upto $200 \mathrm{~ms}$ before the Q wave, it is very marked (grade II)) [25]. The premature mitral valve closure is beneficial in the sense that the high LVDP (LV diastolic pressure) is not transmitted to the pulmonary venous system, thus preventing pulmonary edema and left heart failure. When LVDP exceeds the LA 
pressure, the protection offered by premature mitral valve closure is lost, the opening of mitral valve occurs in late diastole, leading to diastolic mitral regurgitation which is usually effective to lower the LVDP and thus left atrium serves as a reservoir for blood regurgitant from the aorta to left ventricle.

The differential features of acute and chronic AR are shown in Table 1.

In left-sided endocarditis, vegetations usually develop on the edges of the valve leaflets, more prone for peripheral embolism and embolic events may occur before the clinical recognition of the disease as "silent embolism", especially in spleen and kidney, and $30 \%$ of patients have renal or splenic infarcts at the time of diagnosis. Renal function may deteriorate as the result of worsening hemodynamics and emboli to kidney can lead to abscess formation, presenting as flank pain, pyuria, or hematuria and cause "flea-bitten" appearance of cortex with focal segmental necrosis of the glomerular tuft [26].

\subsection{Echocardiographic Features}

Echocardiography plays a key role in the diagnosis of infective endocarditis and the vegetation, the hallmark lesion of infective endocarditis is a majpr echocardiographuc criterion for its detection. Vegetation is a bulky, friable, frequently pedunculated mass composed of fibrin strands, platelets, blood cell debris, bacteria and presents as an oscillating mass attached to a valvular structure, with a motion independent to that of the valve. It may be also seen as non-oscillating masses with atypical location. Transthoracic echocardiography detects $70 \%$ of vegetations $>6 \mathrm{~mm}$ and $25 \%$ of vegetation $<5 \mathrm{~mm}$. The sensitivity of transthoracic echocardiography for the diagnosis of vegetation is about $75 \%$ and the vegetation size of $2 \mathrm{~mm}$ in diameter might be the critical size required for echocardiographic identification. The thickened echoes emanating from the valvular vegetation on aortic echogram appear to be specific for bacterial endocarditis of aortic valve as in Figures 3-9.

Table 1. The differential features of acute and chronic AR.

\begin{tabular}{ccc}
\hline & Acute AR & Chronic AR \\
\hline Heart rate & Increased & May be normal \\
Systemic arterial pulse pressure & Not significantly increased & Increased \\
Aortic systolic pressure & Not increased & Increased \\
Aortic diastolic pressure & Not decreased & Markedly decreased \\
Peripheral vascular resistance & Increased & Decreased \\
LV compliance & Not increased & Increased \\
LV end diastolic pressure & Markedly increased & Normal \\
LV ejection velocity & Not significantly increased & Increased \\
Regurgitant volume & Increased & Increased \\
Effective stroke volume & Not increased & Increased \\
Effective cardiac output & Decreased & May be normal \\
Ejection fraction & Not increased & Maintained normal for long periods
\end{tabular}


When endocarditis involves the aortic leaflets, the resultant acute, severe regurgitation as shown in Figures 10, Figure 11 and Figure 15, may often causes dilated left ventricle as in Figure 12 and a prominent aorta as in Figure 14.

Secondary infection of mitral valve is a possible finding in primary aortic valve endocarditis. Large aortic valve vegetations $(>6 \mathrm{~mm})$ prolapse into the left ventricular outflow tract and "kiss" the ventricular surface of the anterior mitral leaflet with the development of a vegetation [27] [28] [29]. The left ventricular outflow tract endocarditis may represents the initial site of infection with a possibility to spread by contiguity to both left-sided valves, the mitral and aortic [30], causes the "mitral-kissing vegetation" with a higher prevalence of embolic events [31].

\subsection{Management}

Endocarditis normally presents with fever, murmur, tachypnea, tachycardia, hyperfibrinogenemia, anemia and leukocytosis [32] [33]. Early and adequate diagnosis is important for the prognosis and treatment of patients with infective endocarditis. New laboratory and molecular analysis techniques have been adapted for recognizing previously unidentified species as etiological agents of infective endocarditis.

The management of infective endocarditis comprises antibiotic therapy, intensive medical care and surgery as three main pillars of treatment.

\subsection{Medical Therapy}

Bacterial endocarditis must be treated with antibiotics. The objective is the selection of antibiotic based on the sensitivity shown by the antibiogram, but treatment generally begins with an empirical wide-spectrum antibiotic until the hemoculture results are ready [34]. Antibiotics commonly used are penicillin associated with gentamycin [35] and the treatment duration depends on the improvement and resolution of clinical signs, echocardiographic findings, white blood cells, and fibrinogen reduction within normal limits. Traditionaly, prolonged ( 4 - 6 weeks) treatment is mandatory to kill the dormant bacteria clustered in the infected foci [36]. The mean duration of antibiotic therapy was 5 weels and it is possible that similar results can be obtained after as little as two weeks of therapy [37] [38] [39], especially in uncomplicated NVE (native valve endocarditis) with normal renal function [40].

Almost all patients with acute aortic regurgitation (AR) exhibit tenuous hemodynamics and initial stabilization is required in the intensive care unit. Medical therapy is directed at reducing pulmonary venous congestion, reduction in systolic blood pressure to relieve the afterload and maximizing the cardiac output. Intravenous vasodilator and diuretic therapy can be effective and the principal aim of medical treatment is to optimize clinical status. The nitroprusside with an initial dose of 0.10 to $0.20 \mu \mathrm{g} / \mathrm{kg} / \mathrm{mt}$, gradually increased to attain the desired hemodynamic effects as a reduction in LV filling pressure to $15 \mathrm{mmHg}$ or 
less and an increase in cardiac output that would ensure adequate tissue oxygen delivery, usually a cardiac index $>2.5 \mathrm{~L} / \mathrm{mt} / \mathrm{m}^{2}$ while maintaining a systemic blood pressure of $\geq 90 \mathrm{mmHg}$.

Patients with grade I premature mitral valve closure without clinical heart failure can be managed by medical therapy. Anticoagulation is not indicated for patients with endocarditis because of the risk of hemorrhagic neurological events [41]. It prevents neither the formation nor the embolization of vegetation as separation of small fragments from the infected vegetations. Three quarters of embolism occurs before the beginning of antibiotic treatment [42] and the embolic risk decreases over time, from $15 \%$ after one week of treatment to $1 \%$ after 4 weeks [43].

\subsection{Atrial Pacing}

Patients with aortic regurgitation are more likely to have ventricular dysrhythmias and supraventricular premature depolarizations are more commonly observed in severe regurgitation [44]. Nevertheless, sinoatrial arrest (presented as heart rate $>30 \mathrm{bpm}$ ) was detected and it is physiological due to high vagal tone as a result of activation of baroreceptors located in aortic callus and carotid sinus, which prolongs the period of atrial filling as a compensatory mechanism to maintain the stroke volume and blood pressure partially masking the vagal tone.

Increasing the heart rate by atrial pacing has been shown to decrease the regurgitant volume, left ventricular end-diastolic pressure and pulmonary venous pressure in patients with severe aortic regurgitation.

\subsection{Aortic Valve Replacement (AVR)}

Heart failure due to the development of acute aortic regurgitation is currently the leading cause of death from infective endocarditis [45]. When patients respond dramatically to medical therapy, surgical therapy can be delayed until heart failure and infection are controlled and the patient is more stable [46]. The purpose of stabilizing congestive heart failure was to allow sterilization of the blood stream prior to operative intervention to reduce the incidence of valve dehiscence and new nidi of infection.

Aortic valve replacement (AVR) can be safely and effectively accomplished during the course of active infective endocarditis and that urgent valve replacement should be considered [47] in patients who develop heart failure due to valve destruction.

Anaesthetic management may be difficult due to hypotension despite hyperdynamic LV function and hypoxaemia due to severe pulmonary edema can complicate induction in patients with acute aortic regurgitation.

\subsection{Transcatheter AVR}

It is difficult to arrive at a standardized definition of appropriate candidates for TAVI (Transcatheter aortic valve implantation), i.e., patients who are considered 
too high-risk for conventional AVR and would derive more benefit from the transcatheter procedure.

The acute onset of severe aortic regurgitation (AR) is a medical emergency due to the inability of the left ventricle to quickly adapt to the abrupt increase in end-diastolic volume caused by the regurgitant flow and results in hypotension [48]. These patients are contraindicated for surgical treatment because of high surgical risk. Hence, the transcatheter AVR procedure, might represent a successful and life-saving intervention for treatment of patients with severe aortic regurgitation who present with acute refractory cardiogenic shock [49].

The first reports of minimally invasive transfemoral transcatheter AVR [50] and the first successful transapical TAVI without CPB (cardiopulmonary bypass) using the Cribier-Edwards Balloon Expandable Valve (Sapien TM valve) in humans were reported in 2006 [51] [52]. TAVI is recommended mainly for patients with calcific aortic stenosis with or without regurgitation in elderly patients ( $>65$ years) and it is not offered to patients with isolated rheumatic aortic valve disease. This procedure needs more accurate assessment of aortic annular size to determine the size of transcatheter valve and it should be $\leq 29 \mathrm{~mm}$ since the largest valve size is $29 \mathrm{~mm}$. Furthermore, transcatheter valves are unlikely to have durability comparable to the best surgical tissue valves and had a high incidence of paravalvular leak, which has been shown to have a negative impact on long-term outcomes. As a result of some encouraging outcomes from PARTNER trial, the SAPIENTM valve was approved for commercial use in inoperable patients with symptomatic aortic stenosis [53].

Few cases of infective endocarditis (IE) after TAVR (transcatheter aortic valve replacement) had been reported and its incidence ranges between $0 \%$ and $2.3 \%$ [54]. The space between the bioprosthesis and the native aortic valve cusp might be a suitable nidus for the accumulation of pathogens during transient bacteremia [55].

\subsection{Surgical AVR}

Since the mortality with medical therapy alone is extremely high, early aortic-valve replacement has been undertaken at several institutions, with a substantial reduction in mortality [56]. Clinically, early surgery was considered to be a greater risk than delayed surgery because of tissue inflammation and the surgery was technically more difficult. Surgery should be rapid in case of hemodynamic deterioration, uncontrolled infection and large, mobile vegetations. Determination of proper timing of surgical intervention in patients with heart failure, controlled medically and those with neurological complications is difficult. Ideally, aortic-valve replacement can be performed after the completion of antibiotic therapy, but before the progressive destruction of valvular and myocardial tissue. In fact, the duration of antibiotic treatment before surgery does not appear to influence the perioperative mortality, nor the rate of recurrent infective endocarditis [57]. Aortic valve surgery may be timed with reference to whether 
the premature mitral valve closure is mild or severe. Very early mitral-valve closures had severely volume-overloaded ventricles and are candidates for early valve replacement. Patients with grade II premature mitral valve closure require urgent AVR and grade II premature mitral valve closure and mitral regurgitation should undergo emergent AVR.

Systemic embolism is relatively a weak indication for early valve replacement, but an exception is fungal endocarditis, the operation appears to be indicated at the time of diagnosis to eradicate the infection [58] [59]. Griffin and associates have recommended prompt valve replacement even in patients with mild congestive heart failure in order to prevent sudden death due to coronary embolism [60]. The indications of surgical intervention for vegetations with high risk of embolism are shown in Table 2.

In presence of stroke, delay the surgery for 2 - 3 weeks [62] because of major neurological risk and the presence of coma is a contraindication to surgery.

Valve repair is potentially applicable to the atrio-ventricular valves (mitral and tricuspid) and all the necrotic and infected tissue need to be excised and the defects are to be repaired.

For valve replacement in aortic valve endocarditis, homografts are especially useful since they have greater resistance to infection compared to prosthetic valves, but had high early calcification rates. Translocation of the aortic valve (Ross procedure-diseased aortic valve) is replaced with the patient's own pulmonary valve (pulmonary autograft) can be an alternative in prosthetic valve endocarditis and mechanical valves are preferred in younger individuals, anticoagulants should be discontinued if CNS events occur during therapy.

\subsection{Endovascular Therapy}

Although progressive heart failure and systemic embolism are well-established indications for valve replacement in patients with bacterial endocarditis, there is uncertainty regarding the operative priority in patients with both intracranial aneurysm and acute heart failure. If valve replacement is selected first, cardiopulmonary bypass with systemic heparinization could cause lethal neurologic deficits [63]. A bioprosthetic valve, which does not require anticoagulation therapy, may be preferable to a mechanical valve in such conditions.

Septic emboli from vegetation can cause intracranial infected aneurysm and one-third resolve completely by the $4-6$ weeks of antibiotic therapy. If there is a ruptured mycotic aneurysm, it must be resected, clipped or embolised before

Table 2. The high risk vegetations with embolic potentials as an indication for surgical interventions [61].

Size $>15 \mathrm{~mm}$

Extreme mobility

Continuous increase in size despite adequate treatment

Persistence after 2 weeks of adequate antibiotic therapy 
cardiac surgery. Urgent cerebral angiography and an endovascular approach to intracranial infected aneurysm, especially for solitary and peripheral lesions, is an acceptable option for some patients with active endocarditis and severely damaged valves.

Minimally invasive endovascular approach is used to embolize the aneurysm. For bacterial aneurysms, detachable balloon technique had been proven to be a simple procedure [64]. Coil embolization has steadily replaced neurosurgical therapy in ISAT (International Subarachnoid Aneurysm Trial) [65] and Guglielmi introduced the detachable platinum coil in 1989. Another new technique is injection of N-butyl-cyanoacrylate glue into the affected aneurysm.

The decision to use a coil or cyanoacrylate as an occlusive device depends on the location of the aneurysm. Cyanoacrylate is the logical choice if the aneurysm can be reached with a microcatheter since it permits simultaneous sealing of the aneurysm. The detachable coils may have the risk of perforating the inflamed and friable aneurysmal wall [66].

The endovascular techniques are preferred since they avoid craniotomy and the surgical handling of the swollen brain and also in patients who use anticoagulant drugs due to heart valve replacement [67].

\subsection{Outcome}

If heart failure is present, the mortality rate of native valve infective endocarditis is $55 \%-85 \%$ in case of medical treatment only and $10 \%-35 \%$ in operated patients. Heart failure also increases the perioperative mortality rate from $5 \%$ $10 \%$ in patients without heart failure to $15 \%-35 \%$ in patients with heart failure. Perivalvular infection such as abscesses and intracardiac fistulas occur in $10 \%$ $40 \%$ of aortic valve endocarditis [68] and conduction disturbances are very specific for perivalvular infection [69]. Delaying surgery increases the risk of perivalvular infection and also increases the perioperative mortality [70].

The risk of death in individuals with aortic insufficiency, dilated ventricles and normal ejection fraction with asymptomatic is about $0.2 \%$ /year. Risk increases if the ejection fraction decreases or if the individual develops symptoms [71]. Left ventricular dysfunction determines to an extent the outlook for severity of aortic regurgitation and cardiovascular insufficiency is the largest single cause of postoperative mortality [72].

In the absence of operative intervention, the development of aortic regurgitation due to infective endocarditis is associated with a mortality of approximately $50 \%$ because of progressive hemodynamic deterioration. Early mortality of $27 \%$ for valve replacement occurs during the active stage of infection versus $12 \%$ in the healed stage [73]. In case of transcatheter aortic valve implantation (TAVI) procedure for "inoperable" patients, the 30 -day mortality is typically $<10 \%$ and 1 -year survival following TAVI has ranged from $65 \%$ to $80 \%$. For endovascular therapy (clipping and coiling of infected intracranial aneurysm), the relative risk of poor outcome was $0.76 \%$ after 1 -year of follow-up [74]. 


\subsection{Follow-Up}

The rate of recurrence of infective endocarditis at 5-year follow-up is around $1.5 \%$ per patient-year. The term reinfection is primarily used when a different microorganism produces a new episode of infective endocarditis in high risk patients such as previous valve disease or IV drug use. Relapse refers to a repeat episode of infective endocarditis, caused by the same microorganism as in previous episode due to incomplete treatment, suboptimal choice of initial antibiotics and persistent foci of infection. The occurrence of sudden death is mainly related to infection, as a result of ventricular septal erosion, producing complete heart block during medical therapy and also may occur due to coronary embolism after aortic valve replacement in infective endocarditis [75].

On follow-up for 2 months, the vegetation size was stable, but the aortic regurgitation decreases with an improvement in LV function on continuation of antifailure measures in this patient.

\subsection{IE Prophylaxis}

NICE (National Institute of Clinical Excellence) guidance [76] suggests that preoperative antibiotic prophylaxis is no longer routinely recommended due to allergic reactions of antibiotic therapy, but still advised in high risk patients such as acquired valvular heart disease, previous valve replacement and congenital structural heart diseases, excluding the repaired atrial or ventricular septal defects or patent ductus arteriosus.

\subsection{Case Analysis}

Since the patient had a bicuspid aortic valve as shown in Figure 8 and a history of rheumatic fever during childhood, rheumatic inflammation occurred on the aortic valve and harboured the infective vegetation through the vascular access during the treatment of febrile episodes.

Patients with infective endocarditis are at risk of developing acute aortic regurgitation and the ECG can appear normal as in Figure 1 and the chest X-ray usually shows pulmonary edema with normal heart size. A dilated left ventricular cavity with a normal left atrium as in Figure 12 indicates that the volume overload on the left ventricle resulting a compensatory mechanism to maintain an adequate forward stroke volume by accomodating a large regurgitant fraction without an increase in end-diastolic pressure. The heart rate appeared normal $(87 \mathrm{bpm})$ as the result of this compensation.

Even though the aortic regurgitation is acute as in Figure 10 which showed a steep deceleration slope with a narrow width of regurgitant jet due to endocarditic lesion of aortic valve (endocarditic regurgitation). It is compensated in this patient and showed a lesser degree of decompensation as moderate LV dysfunction with an ejection fraction of $42 \%$ as in Figure 13, necessitating elective aortic valve replacement along with removal of vegetations with a mechanical prosthetic valve. Anticoagulation with warfarin to maintain the INR (international normailised ratio) between 2 to 3 is indicated after the clearance of active stage 
of endocarditis with antibiotic therapy and surgery.

\section{Conclusion}

Complicated left-sided native valve infective endocarditis remains a serious disease with significant mortality and morbidity. The aortic valve is most commonly affected site in infective endocarditis patients without congenital heart disease [77]. Vascular-access-related infections are major source of bacteremia in this population [78]. Antimicrobial therapy can offer a curative treatment in only $50 \%$ of cases of infective endocarditis. Patients with large vegetations, intracardiac abscess ( $9 \%-14 \%)$ or persisting infection (9\% - 11\%) almost always need surgery and most patients require valve replacement.

\section{Conflicts of Interest}

The author declares no conflicts of interest regarding the publication of this paper.

\section{References}

[1] Beynon, R.P., Bahl, V.K. and Prendergast, B.D. (2006) Infective Endocarditis. British Medical Journal, 12, 334-339. https://doi.org/10.1136/bmj.333.7563.334

[2] Prendergast, B.D. (2006) The Changing Face of Infective Endocarditis. Heart, 92, 879-885. https://doi.org/10.1136/hrt.2005.067256

[3] Fedak, P.W., Verma, S., David, T.E., Leask, R.L., Weisel, R.D. and Butany, J. (2002) Clinical and Pathophysiological Implications of a Bicuspid Aortic Valve. Circulation, 106, 900-904. https://doi.org/10.1161/01.CIR.0000027905.26586.E8

[4] Ward, C. (2000) Clinical Significance of the Bicuspid Aortic Valve. Heart, 83, 81-85. https://doi.org/10.1136/heart.83.1.81

[5] Cohen, L. and Freedman, L.R. (1961) Damage to the Aortic Valve as a Cause of Death in Bacterial Endocarditis. Annals of Internal Medicine, 55, 562-564. https://doi.org/10.7326/0003-4819-55-4-562

[6] Krishnaswami, V., et al. (1976) Surgical Treatment of Acute Aortic Regurgitation in Infective Endocarditis. The Annals of Thoracic Surgery, 22, 464-472. https://doi.org/10.1016/S0003-4975(10)64455-4

[7] Lin, S.-C., Liu, S.-C. and Tseng, C.-D. (2009) Infective Endocarditis at Bicuspid Aortic Valve Complicated with Severe Aortic Regurgitation and Rupture of Intracranial Infective Aneurysm: Report of a Case with Literature Review. Taiwan Critical Care Medicine, 10, 318-325.

[8] Dillon, J.C., Feigenbaum, H., Konecke, L.L., et al. (1973) Echocardiographic Manifestations of Valvular Vegetations. American Heart Journal, 86, 698-704. https://doi.org/10.1016/0002-8703(73)90350-5

[9] Osman, S. and Carter, W. (2013) Endocarditis. In: Adams, J.G., et al., Eds., Emergency Medicine Clinical Essentials, 2nd Edition, Elsevier, Philadelphia, 530-546.

[10] Bayer, A.S., Bolger, A.F., Taubert, K.A., Wilson, W., et al. (1998) Diagnosis and Management of Infective Endocarditis and Its Complications. Circulation, 98, 2936-2948. https://doi.org/10.1161/01.CIR.98.25.2936

[11] Tunkel, A.R. and Pradhan, S.K. (2002) Central Nervous System Infections in Injec- 
tion Drug Users. Infectious Disease Clinics of North America, 16, 589-605. https://doi.org/10.1016/S0891-5520(02)00015-6

[12] Misser, S.K., Lalloo, S. and Ponnusamy, S. (2005) Intracranial Mycotic Aneurysm Due to Infective Endocarditis-Successful NBCA Glue Embolization. South African Medical Journal, 95, 397-399, 403-404.

[13] Salgado, A.V., Furlan, A.J. and Keys, T.F. (1987) Mycotic Aneurysm, Subarachnoid Hemorrhage, and Indications for Cerebral Angiography in Infective Endocarditis. Stroke, 18, 1057-1060. https://doi.org/10.1161/01.STR.18.6.1057

[14] Corr, P., Wright, M. and Handler, L.C. (1995) Endocarditis-Related Cerebral Aneurysms: Radiologic Changes with Treatment. American Journal of Neuroradiology, 16, 745-748.

[15] Masuda, J., Yutani, C., Waki, R., Ogata, J., Kuriyama, Y. and Yamaguchi, T. (1992) Histopathological Analysis of the Mechanisms of Intracranial Hemorrhage Complicating Infective Endocarditis. Stroke, 23, 843-850. https://doi.org/10.1161/01.STR.23.6.843

[16] Kannoth, S., Iyer, R., Thomas, S.V., Furtado, S.V., et al. (2007) Intracranial Infectious Aneurysm: Presentation, Management and Outcome. Journal of the Neurological Sciences, 256, 3-9. https://doi.org/10.1016/j.jns.2007.01.044

[17] Stason, W.B., De Sanctis, R.W., Weinberg, A.N., et al. (1968) Cardiac Surgery in Bacterial Endocarditis. Circulation, 38, 514-523. https://doi.org/10.1161/01.CIR.38.3.514

[18] Rees, J.R., Epstein, E.J., Criley, J.M., et al. (1964) Hemodynamic Effects of Severe Aortic Regurgitation. British Heart Journal, 26, 412-421. https://doi.org/10.1136/hrt.26.3.412

[19] Wigle, E.D. and Labrosse, C.J. (1965) Sudden, Severe Aortic Insufficiency. Circulation, 32, 708-720. https://doi.org/10.1161/01.CIR.32.5.708

[20] Nadji, G., Rusinaru, D., Remadi, J.P., Jeu, A., Sorel, C. and Tribouilloy, C. (2009) Heart Failure in Left-Sided Native Valve Infective Endocarditis: Characteristics, Prognosis, and Results of Surgical Treatment. European Journal of Heart Failure, 11, 668-675. https://doi.org/10.1093/eurjhf/hfp077

[21] Stout, K.K. and Verrier, E.D. (2009) Acute Valvular Heart Disease: Changing Concepts in Disease Management. Circulation, 119, 3232-3241. https://doi.org/10.1161/CIRCULATIONAHA.108.782292

[22] Botvinick, E.H., Schiller, N.B., Wickramasekasan, R., Klausner, S.C. and Gertz, E. (1975) Echocardiographic Demonstration of Early Mitral Valve Closure in Severe Aortic Insufficiency, Its Clinical Implications. Circulation, 51, 836-847. https://doi.org/10.1161/01.CIR.51.5.836

[23] Flint, A. (1886) On Cardiac Murmurs. American Journal of Medical Sciences, 91, 27. https://doi.org/10.1097/00000441-188601000-00002

[24] Pridle, R.B., Benham, R. and Oakley, C.M. (1971) Echocardiography of the Mitral Valve in Aortic Valve Disease. British Heart Journal, 33, 296-304. https://doi.org/10.1136/hrt.33.2.296

[25] Hamirani, Y.S., Dietl, C.A., Voyles, W., Peralta, M., Begay, D. and Raizada, V. (2012) Acute Aortic Regurgitation. Circulation, 126, 1121-1126. https://doi.org/10.1161/CIRCULATIONAHA.112.113993

[26] Aretz, H. and Krandin, R. (2010) Cardiac Infections. In: Krandin, R., Ed., Diagnostic Pathology of Infectious Disease, Saunders, Philadelphia, 8, 189-213. https://doi.org/10.1016/B978-1-4160-3429-2.00008-0 
[27] Oakley, C. (2002) The Mitral Kissing Vegetation. European Heart Journal, 23, 11-12. https://doi.org/10.1053/euhj.2001.2811

[28] Piper, C., Hetzer, R., Korfer, R., et al. (2002) The Importance of Secondary Mitral Valve Involvement in Primary Aortic Valve Endocarditis; The Mitral Kissing Vegetation. European Heart Journal, 23, 79-86. https://doi.org/10.1053/euhj.2001.2689

[29] Bhattacharyya, S., Hickman, M. and Lythall, D. (2005) Mitral Valve "Kissing" Vegetation. Heart, 91, e43.

[30] Jacovelli, F., Scicchitano, P., Zanna, D., Marangelli, V. and Favale, S. (2012) Left Ventricle Outflow Tract Vegetation, Embolism and Troponin Rise: An Infective Endocarditis Case Report. Internal and Emergency Medicine, 7, S145-S147.

[31] Becker, A.E. (1974) Cardiac Complications of Infectious Endocarditis of the Aortic Valve. European Journal of Cardiology, 1, 467-472.

[32] Dorner, C.A., Saez, D., Larenas, J. and Godoy, A.F. (2014) Aortic Regurgitation Associated with Chronic Bacterial Endocarditis in One Adult Thoroughbred Gelding. Archivos De Medicina Veterinaria, 46, 263-269. https://doi.org/10.4067/S0301-732X2014000200012

[33] Maxson, A. and Reef, V. (1997) Bacterial Endocarditis in Horses: Ten Cases (1984-1995). Equine Veterinary Journal, 29, 394-399. https://doi.org/10.1111/j.2042-3306.1997.tb03146.x

[34] Sage, A. (2010) Fever: Endocarditis and Pericarditis. In: Marr, C. and Bowen, M., Eds., Cardiology of the Horse, 2nd Edition, Saunders, Philadelphia, 217-225. https://doi.org/10.1016/B978-0-7020-2817-5.00022-5

[35] Seco Diaz, O., Sleeper, M., Reef, V. and Acland, M. (2000) Aortitis in a Paint Gelding. Equine Veterinary Journal, 32, 354-357. https://doi.org/10.2746/042516400777032255

[36] Moreillon, P. (2010) Endocarditis and Enteritis. In: Cohen, J., Ed., Infectious Diseases, 3rd Edition, Missouri, 47, 514-528.

[37] Crosby, I.K., Carrell, R. and Reed, W.A. (1972) Operative Management of Valvular Complications of Bacterial Endocarditis. The Journal of Thoracic and Cardiovascular Surgery, 64, 235-246.

[38] Fowler, N.O., Hamburger, M.H. and Bove, K.E. (1967) Aortic Valve Perforation. The American Journal of Medicine, 42, 539-546. https://doi.org/10.1016/0002-9343(67)90053-8

[39] Wlndsor, H.M., Golding, L.A. and Shanahan, M.X. (1972) Cardiac Surgery in Bacterial Endocarditis. The Journal of Thoracic and Cardiovascular Surgery, 64, 282.

[40] Cahill, T.J., Baddour, L.M. and Habib, G. (2017) Challenges in Infective Endocarditis. Journal of the American College of Cardiology, 69, 325-344. https://doi.org/10.1016/j.jacc.2016.10.066

[41] Snygg-Martin, U., Rasmussen, R.V., Hassager, C., Bruun, N.E., Andersson, R. and Olaison, L. (2011) Warfarin Therapy and Incidence of Cerebrovascular Complications in Left-Sided Native Valve Endocarditis. European Journal of Clinical Microbiology \& Infectious Diseases, 30, 151-157. https://doi.org/10.1007/s10096-010-1063-3

[42] Heiro, M., Nikoskelainen, J., Engblom, E., et al. (2000) Neurologic Manifestations of Infective Endocarditis. A 17-Year Experience in a Teaching Hospital in Finland. Archives of Internal Medicine, 160, 2781-2787. https://doi.org/10.1001/archinte.160.18.2781

[43] Alestig, K., Hogevik, H. and Olaison, L. (2000) Infective Endocarditis: A Diagnostic 
and Therapeutic Challenge for the New Millennium. Scandinavian Journal of Infectious Diseases, 32, 343-356. https://doi.org/10.1080/003655400750044908

[44] Marr, C. and Patteson, M. (2010) Echocardiography. In: Marr, C. and Bowen, M., Eds., Cardiology of the Horse, 2nd Edition, Saunders, New York, 105-126. https://doi.org/10.1016/B978-0-7020-2817-5.00014-6

[45] Mann, T., McLaurin, L., Grossman, W. and Craige, E. (1975) Assessing the Hemodynamic Severity of Acute Aortic Regurgitation Due to Infective Endocarditis. The New England Journal of Medicine, 293, 108-113. https://doi.org/10.1056/NEJM197507172930302

[46] Robert, A. and O'Rourke, R.A. (2018) Recognition and Treatment of Acute Aortic Regurgitation. Journal of Intensive Care Medicine, 1, 33-46.

[47] Wise, J.R., Cleland, W.P., Hallide-Smith, K.A., Bentall, H.H., Goodwin, J.F. and Oakley, C.M. (1971) Urgent Aortic-Valve Replacement for Acute Aortic Regurgitation Due to Infective Endocarditis. The Lancet, 298, 115-121. https://doi.org/10.1016/S0140-6736(71)92300-2

[48] Otto, C.M., Gaasch, W.H. and Yeon, S.B. (2018) Acute Aortic Regurgitation in Adults.

[49] Achkouty, G., Zannis, N.A.K., Veugeois, A. and Caussin, C. (2018) Transcatheter Aortic Valve Replacement for Severe Aortic Regurgitation with Acute Refractory Cardiogenic Shock. Canadian Journal of Cardiology, 34, 342.e5-342.e7. https://doi.org/10.1016/j.cjca.2017.11.024

[50] Webb, J.G., Chandavimol, M., Thompson, C.R., et al. (2006) Percutaneous Aortic Valve Implantation Retrograde from the Femoral Artery. Circulation, 113, 842-850. https://doi.org/10.1161/CIRCULATIONAHA.105.582882

[51] Ye, J., Cheung, A., Lichtenstein, S.V., et al. (2006) Transapical Aortic Valve Implantation in Humans. The Journal of Thoracic and Cardiovascular Surgery, 131, 1194-1196. https://doi.org/10.1016/j.jtcvs.2006.01.026

[52] Lichtenstein, S.V. (2006) Closed Heart Surgery: Back to the Future. The Journal of Thoracic and Cardiovascular Surgery, 131, 941-943. https://doi.org/10.1016/j.jtcvs.2006.01.025

[53] Ye, J., Soon, J.L. and Webb, J. (2012) Aortic Valve Replacement vs. Transcatheter Aortic Valve Implantation: Patient Selection. Annals of Cardiothoracic Surgery, 1, 194-199.

[54] Loh, P.H., Bundgaard, H.S. and Ndergaard, L. (2013) Infective Endocarditis Following Transcatheter Aortic Valve Replacement: Diagnostic and Management Challenges. Catheterizarion and Cardiovascular Interventions, 81, 623-627. https://doi.org/10.1002/ccd.24368

[55] Puls, M., Eiffert, H., Hinlich, M., Schondube, F., Hasenfu, B.G., Seipelt, R. and Schillinger, W. (2013) Prosthetic Valve Endocarditis after Transcatheter Aortic Valve Implantation: The Incidence in a Single-Centre Cohort and Reflections on Clinical, Echocardiographic and Prognostic Features. Eurointervention, 8, 1407-1418. https://doi.org/10.4244/EIJV8I12A214

[56] Olaison, L. and Pettersson, G. (2002) Current Best Practices and Guidelines Indications for Surgical Intervention in Infective Endocarditis. Infectious Disease Clininics of North America, 16, 453-475. https://doi.org/10.1016/S0891-5520(01)00006-X

[57] D’Udekem, Y., David, T.E., Feindel, C.M., et al. (1997) Long-Term Results of Surgery for Active Infective Endocarditis. European Journal of Cardiothoracic Surgery, 11, 46-52. https://doi.org/10.1016/S1010-7940(96)01020-2 
[58] Kay, J.H., Bernstein, S., Tsuji, H.K., et al. (1968) Surgical Treatment of Candida Endocarditis. Journal of American Medical Association, 203, 621-626. https://doi.org/10.1001/jama.1968.03140090005002

[59] Weinstein, L. and Schlesinger, J. (1973) Treatment of Infective Endocarditis. Progress in Cardiovascular Diseases, 16, 275-302. https://doi.org/10.1016/S0033-0620(73)80002-7

[60] Griffin, F.M., Jones, G. and Cobbs, G.C. (1972) Aortic Insufficiency in Bacterial Endocarditis. Annals of Internal Medicine, 76, 23-28. https://doi.org/10.7326/0003-4819-76-1-23

[61] Al-Attar, N. (2008) Infective Endocarditis. European Society of Cardiology, 7, No. 15.

[62] Gillinov, A.M., Shah, R.V., Curtis, W.E., et al. (1996) Valve Replacement in Patients with Endocarditis and Acute Neurologic Deficit. Annals of Thoracic Surgery, 61, 1125-1130. https://doi.org/10.1016/0003-4975(96)00014-8

[63] Utoh, J., Miyauchi, Y., Goto, H., Obayashi, H. and Hirata, T. (1995) Endovascular Approach for an Intracranial Mycotic Aneurysm Associated with Infective Endocarditis. The Journal of Thoracic and Cardiovascular Surgery, 110, 557-559. https://doi.org/10.1016/S0022-5223(95)70259-8

[64] Micheli, F., Schteinschnaider, A., Plaghos, L.L., Melero, M., Mattar, D. and Parera, I.C. (1989) Bacterial Cavernous Sinus Aneurysm Treated by Detachable Balloon Technique. Stroke, 20, 1751-1754. https://doi.org/10.1161/01.STR.20.12.1751

[65] Fiehler, J. and Byme, J.V. (2009) Factors Affecting Outcome after Endovascular Treatment of Intracranial Aneurysms. Current Opinion in Neurology, 22, 103-108. https://doi.org/10.1097/WCO.0b013e32831af1c1

[66] Chapot, R., Houdart, E., Saint-Maurice, J.P., Aymard, A., Mounayer, C., Lot, G. and Merland, J.J. (2002) Endovascular Treatment of Cerebral Mycotic Aneurysms. Radiology, 222, 389-396. https://doi.org/10.1148/radiol.2222010432

[67] Sarica, F.B., Erdogan, B., Tufan, K., Cekinmez, M., Kizilkilic, O., Sen, O. and Altinors, M.N. (2008) Endovascular Treatment of Primary Infectious Aneurysm in Childhood: A Case Report. Turkish Neurosurgery, 18, 47-51.

[68] Choussat, R., Thomas, D., Isnard, R., et al. (1999) Perivalvular Abscesses Associated with Endocarditis: Clinical Features and Prognostic Factors of Overall Survival in a Series of 233 Cases, Perivalvular Abscesses French Multicentre Study. European Heart Journal, 20, 232-241. https://doi.org/10.1053/euhj.1998.1240

[69] Knosalla, C., Weng, Y., Yankah, A.C., et al. (2000) Surgical Treatment of Active Infective Aortic Valve Endocarditis with Associated Periannular Abscess. 11 Year Results. European Heart Journal, 21, 490-497. https://doi.org/10.1053/euhj.1999.1877

[70] Blumberg, E.A., Karalis, D.A., Chandrasekaran, K., et al. (1995) Endocarditis-Associated Paravalvular Abscesses. Do Clinical Parameters Predict the Presence of Abscess? Chest, 107, 898-903. https://doi.org/10.1378/chest.107.4.898

[71] Bonow, R.O. (2013) Chronic Mitral Regurgitation and Aortic Regurgitation. Journal of the American College of Cardiology, 61, 693-701.

https://doi.org/10.1016/j.jacc.2012.08.1025

[72] Black, S., O’Rourke, R.A. and Karliner, J.S. (1974) Role of Surgery in the Treatment of Primary Infective Endocarditis. American Journal of Medicine, 56, 357. https://doi.org/10.1016/0002-9343(74)90617-2

[73] Manhas, D.R., Mohri, H., Hessel, E.A., et al. (1972) Experience with Surgical Management of Primary Infective Endocarditis: A Collected Review of 139 Patients. American Heart Journal, 84, 738. https://doi.org/10.1016/0002-8703(72)90065-8 
[74] Van Der Schaff, I., Algra, A., Wermer, M., et al. (2005) Endovascular Coiling versus Neurosurgical Clipping for Patients with Aneurysmal Subarachnoid Haemorrhage. Cochrane Database of Systematic Reviews, CD003085.

[75] Robinson, M.J. and Ruedy, J. (1962) Sequelae of Bacterial Endocarditis. American Journal of Medcine, 32, 922-928.

[76] National Institute for Health and Clinical Excellence. Antimicrobial Prophylaxis against Infective Endocarditis. http://guidance,nice.uk/CG64

[77] Dyson, C., Barnes, R.A. and Harrison, G.A.J. (1999) Infective Endocarditis: An Epidemiological Review of 128 Episodes. Journal of Infection, 38, 87-93.

https://doi.org/10.1016/S0163-4453(99)90074-9

[78] Remadi, J.P., Habib, G., Nadji, G., et al. (2007) Predictors of Death and Impact of Surgery in Staphylococcus Aureus Infective Endocarditis. Annals of Thoracic Surgery, 83, 1295-1302. https://doi.org/10.1016/j.athoracsur.2006.09.093 